malabsorption of vitamin $\mathbf{B}_{12}$ and four of these had abnormally low serum levels of the vitamin. We have data on 114 diabetic patients who have had at least $2 \mathrm{~g}$ of metformin daily for at least two years and of these no less than $17 \cdot 5 \%$ had serum levels of vitamin $B_{12}$ at or below the lowest leve of the normal range $(160-900 \mu \mu / \mathrm{ml})$. The fact that this figure is considerably above the $5.6 \%$ of the Belfast workers may be owing to the relatively larger mean daily dose of metformin used in the Aberdeen series $(3.3 \mathrm{~g}$ versus $1.8 \mathrm{~g})$. Just under $10 \%$ of the Aberdeen series also had abnormally low levels of serum folate, but in all but one instance this occurred with normal serum vitamin $B_{12}$ levels. The mean duration of biguanide therapy was similar in both series (4.6 and 4.4 years for Belfast and Aberdeen respectively) but in Aberdeen most of the patients had had phenformin in preference to metformin before 1968 . The change-over to metformin for those requiring more than $100 \mathrm{mg}$ of phenformin a day was effected because of a few cases of serious lactic acidosis associated with the use of larger doses of phenformin, especially after an alcoholic spree. We have not seen lactic acidosis in patients taking up to $4.5 \mathrm{~g}$ of metformin a day.

We would like to support the recommendation of Dr. Tomkin and others that all patients on long-term therapy with metformin should have an annual estimation of serum vitamin $B_{12}$, for it is otherwise quite easy to miss cases of classical macrocytic anaemia and/or signs of subacute combined degeneration of the cord.

We would like to thank Dr. Audrey Dawson and her staff for undertaking the haematological investigations.

JOHN M. STOWERS Diabetic Clinic, Royal Infirma
Aberdeen

Olajide A. O. SMIth was found. This was converted to a proximal jejunogastrostomy. The patient made an uninterrupted recovery, and is continuing to have a normal bowel action and to regain weight.

Mistakes are made. This is not a criticism but a cautionary tale. Diarrhoea does occur after truncal vagotomy, but, before it is given a diagnostic label of "vagotomy diarrhoea," the patient must be thoroughly reinvestigated.-I am, etc.,

Queen Mary's Hospital,

Rosalind M. MANCE

\section{Genital Herpes Infection and Non-specific Urethritis}

SIR,-Dr. C. S. Goodwin and others (28 November, 1970, p. 558) discussed the asymptomatic infection of the male urethra with herpes simplex virus (H.S.V.). H.S.V was isolated from 2 out of 12 males with urethral discharge. The patients had no clinical signs or symptoms of herpes genitalis.

At Karolinska Sjukhuset since 1968 we have studied the incidence of genital H.S.V. infection in patients attending the V.D clinic because of suspected venereal disease. ${ }^{1}$ The specimens for virus isolation were taken from the urethra and collected on the patients' first visit to the clinic. Immediately after sampling the urethral swab was placed in tissue culture tube with GMK-AH 1 cells (established line of Green monkey kidney cells). ${ }^{2}$ In 29 out of 688 males H.S.V. was isolated. Seven of the males with verified H.S.V. infection had no clinical signs or symptoms of herpes genitalis. Their only symptom was urethral discharge. The Table indicates symptoms and hictories in all ou cases of virologically verified genital H.S.V. infection (figures in brackets give the number of patients with gonorrhoea in the respective groups).

\section{Vagotomy Diarrhoea}

SIR,-There has been considerable debate concerning the incidence of incapacitating explosive diarrhoea after truncal vagotomy for peptic ulcer (1 February 1969, p. 302 and 14 February 1970, p. 412).

I would like to report the case of a 42year-old man who was admitted to hospital in September 1970 with the clinical presentation of a perforated chronic duodenal ulcer. This was confirmed and treated at laparotomy by simple suture. Two months later, with no improvement in his symptoms a truncal vagotomy and gastroenterostomy were performed. After this he immediately developed explosive incapacitating diarrhoea up to 15 times daily, which failed to respond to any medical treatment. A diagnosis of vagotomy diarrhoea was made. Four month later it was clear that, from physical, occupational, and social aspects, the patient could not tolerate continuation of his symptoms. He was admitted to hospital for full reinvestigation. The further relevant findings were a history of intense hunger, not satisfied by any amount of food; the presence of undigested food in the stool; and on barium meal and follow through, the passage of barium from the hypopharynx to the caecum in $4 \frac{1}{2}$ minutes.

At laparotomy a terminal ileogastrostomy

- History of clinical H.S.V. infection in the genital region minor lesions, similar to H.S.V. infection, in the genital region

† Grouped vesicles or grouped shallow ulcerations in the genital region

The same technique for virus isolation has been used in a control group. ${ }^{1}$ One hundred and thirty three young males without venereal disease and without history or clinical sign of genital H.S.V. infection were investigated. The rate of genital H.S.V. infection in the control group was none (no virus isolated). patients without typical symptoms and history of genital H.S.V. infection, all with urethral discharge, H.S.V. was the only agent that could be isolated. If virus isolation non-specific urethritis.
To our knowledge none of the authors who previously have reported negative virus isolations from males with non-specific urethritis $^{2} 3$ have used a comparable technique. Nahmias et al. ${ }^{4}$ have reported a prevalence of $0.3 \%$ genital H.S.V. infection in males attending a venereal disease clinic Virus isolation was done only from genital lesions in males with clinical symptoms of genital H.S.V., and the swabs were placed into Hank's buffered salt solution before inoculation of the specimens into tissue culture tubes. Considering the relative lability of H.S.V. Type $2^{5}$ it is to be expected that a method with direct inoculation of the specimen into the tissue culture tube will be a more sensitive method of detecting the virus. -We are, etc.,

S. JEANSSON

L. MoLIN

Department of Clinical Bacteriology,

Section of Virology, and

Department of Dermatology,

Karolinska Sjukhuset, 1 Jeansson, S., and Molin, L., Lancet, 1970, 1, 1064. Fournal, 1968, 99 , 900.

3 Günalp, A., Proceedings of the Society for Experimental Biology and Medicine, 1965, 118, 85 . Nahmias, A. J., et al., British fournal of Venerea Diseases, $1969,45,294$.

Plummer, G., Waner, J. L., Phuangsab, A., and
Goodheart, C. R., fournal of Virology, 1970, 5 , 51 .

\section{Haemodialysis/Transplantation Programme}

SIR,-I have been interested in the logistics of renal dialysis units and I should like to raise a few points regarding the paper by Dr. S. C. Farrow and others on a statistical approach to planning an integrated haemodialysis-transplantation programme (19 June, p. 671).

Firstly, certain important probabilities used in the matrix do not appear to fit the data from which they were derived. The Table giving survival figures should be corrected in the columns given below. It is appreciated that a monthly survival greater than 1.00 is unreal, but such parameters are meaningful when the average "matrix survival" for months 7 to 30 is calculated; this is 0.9897 (or 0.99 ) not 0.98 as given in the Table. (A simple graph of the survivals for these months illustrates that 0.99 gives a closer fit than does 0.98 ). It should be noted that this is the monthly survival for all states, and includes poorer survivals from states with poorer prognoses, such as the months following transplantation.

Table Corrections

From the Table it is obvious that in five had not been performed these patients might well have been classified as suffering from 